Pathophysiology of Haemostasis and Thrombosis
Pathophysiol Haemost Thromb 2005;34:279-283

DOI: $10.1159 / 000093108$
Received: July 14, 2005

Accepted after revision: January 18, 2006

\title{
Influence of Factor V HR2 on Thrombin Generation and Clinical Manifestation in Rare Bleeding Disorders
}

\author{
Rüdiger F. Strey ${ }^{a}$ Annelie Siegemund $^{b}$ Thomas Siegemund $^{b}$ \\ Christine Schubert $^{\mathrm{c}}$ Gudrun Schuster $^{\mathrm{a}}$ Karin Wulffa $^{\mathrm{a}}$ Falko H. Herrmann ${ }^{\mathrm{a}}$ \\ ${ }^{a}$ Department of Human Genetics, EMA University of Greifswald, Greifswald, ${ }^{\mathrm{b}}$ Department of \\ Clinical Biochemistry and Pathobiochemistry, University of Leipzig, Leipzig, and ${ }^{\mathrm{C}}$ Klinikum Erfurt GmbH, \\ Erfurt, Germany
}

\section{Key Words}

Factor V HR2 haplotype · Endogenous thrombin potential $\cdot$ Thrombosis

\begin{abstract}
In this study we investigated the influence of the presence of the factor V HR2 haplotype, defined by the factor $\mathrm{V}$ gene mutation $\mathrm{H} 1299 \mathrm{R}\left(\mathrm{FV}_{\mathrm{HR} 2}\right)$, on thrombin generation. Measurements were performed in platelet-poor plasma of individuals with factor $\mathrm{V}_{\mathrm{HR} 2}$ or factor $\mathrm{V}_{\text {Leiden }}$ in comparison to a control group carrying none of these mutations. Coagulation was triggered by low concentrations of recombinant tissue factor in the presence of activated protein $\mathrm{C}$. Thrombin generation was monitored by a fluorogenic substrate. The endogenous thrombin potential was calculated from the obtained curves. As a result we observed an increased thrombin generation both for individuals heterozygous and homozygous for $\mathrm{FV}_{\mathrm{HR} 2}$. The level of endogenous thrombin potential is in the same range as in samples of patients heterozygous or homozygous for $\mathrm{FV}_{\text {Leiden. }}$. The results indicate that $\mathrm{FV}_{\text {HR2 }}$ plays a role as a risk factor for venous thrombosis in homozygous patients through an increased thrombin
\end{abstract}

generation. The association between different clinical manifestations in individuals with FVII deficiency and endogenous thrombin potential and the presence of $\mathrm{FV}_{\mathrm{HR} 2}$ was studied.

Copyright $(2005$ S. Karger AG, Basel

\section{Introduction}

Activated protein $\mathrm{C}$ (APC) resistance caused by the point mutation $\mathrm{FV}_{\mathrm{R} 506 \mathrm{Q}}\left(\mathrm{FV}_{\text {Leiden }}\right)$ is the most important genetic cause of venous thrombosis [1-8]. Several other mutations of the factor $\mathrm{V}$ gene (M385T, H1299R, M1736V and D2194G) define the factor V HR2 haplotype $\left(\mathrm{FV}_{\mathrm{HR} 2}\right)$ which is associated with a mild APC resistance, but an association with an increased risk of thrombosis is not definitely clarified [9].

An additional clinical effect of APC resistance of $\mathrm{FV}_{\text {Leiden }}$ consists of a moderation in the clinical expression in individuals with severe bleeding disorders. However, this effect has been studied by several groups with inconsistent results [10].

The clinical effect of $\mathrm{FV}_{\mathrm{HR} 2}$ may be explained by two different mechanisms. The first consists in an impaired

\section{KARGER}

Fax +4161306 1234 E-Mail karger@karger.ch www.karger.com
(C) 2005 S. Karger AG, Basel

$1424-8832 / 05 / 0346-0279 \$ 22.00 / 0$

Accessible online at: www.karger.com/pht 
APC cofactor activity of factor $\mathrm{V}$ resulting in a reduced degradation of factor VIIIa [11]. An alternative mechanism is based on a changed ratio of the isoforms $\mathrm{FV}_{1}$ and $\mathrm{FV}_{2}$ in plasma.

In this article we present indications for an association between increased endogenous thrombin potential (ETP) values and the expression of $\mathrm{FV}_{\text {Leiden }}$ as well as $\mathrm{FV}_{\mathrm{HR} 2}$. The association ist studied between different clinical manifestations in individuals with FVII deficiency on the one hand and ETP and the presence of $\mathrm{FV}_{\mathrm{HR} 2}$ on the other hand.

\section{Patients and Methods}

Citrated plasma samples from 8 control subjects without FVLeiden or $\mathrm{FV}_{\mathrm{HR} 2}$ (factor $\mathrm{V}$ wild-type; $\mathrm{FV}_{\mathrm{wt}}$ ) were used as a reference. We used the mutation H1299R as marker for $\mathrm{FV}_{\mathrm{HR} 2}[13,14]$. The $\mathrm{FV}_{\text {Leiden }}$ mutation has been determined according to Bertina et al. [5].

The samples with $\mathrm{FV}_{\text {Leiden }}$ or $\mathrm{FV}_{\mathrm{HR} 2}$ were collected from 7 patients with thrombosis and 7 persons without thrombotic events. The FV mutations of subjects without thrombosis were identified according to corresponding family history. Plasma concentrations of fibrinogen, antithrombin III, homocysteine, protein C, protein $\mathrm{S}$ and coagulation factor XII were within the normal range and lupus anticoagulant testing was negative in all study subjects. Blood samples from patients were collected more than 6 months after the thrombotic event, and in the case of patients on oral anticoagulation (phenprocoumon), the measurements were repeated 4 and 6 weeks after the treatment had been stopped.

Plasma samples of 4 FVII-deficient patients of the Greifswald Factor VII Deficiency Study [15], who are homozygous for the same FVII gene mutation A294V [16], were also included in the present study. Two of these patients had spontaneous bleeding symptoms, such as epistaxis, gum bleeding, hemarthrosis or menorrhagia, and the other 2 patients had never had spontaneous bleeding symptoms in relation to the FVII deficiency (further referred to as 'asymptomatic' subjects). No correlation was found between FVII activity and clinical manifestation in homozygous patients for the identical mutation A294V. There was no significant difference $(p=0.47)$ between FVII:C values of asymptomatic patients $(13 \pm 7)$ and symptomatic patients $(10 \pm 9)$.

All samples, including the pooled normal plasma, were centrifuged for $10 \mathrm{~min}$ at 4,000 $\mathrm{g}$ and the obtained platelet-poor plasma was stored at $-70^{\circ} \mathrm{C}$ until analysis.

Informed consent was obtained from all patients and donors of reference samples.

Measurement of Thrombin Generation in Platelet-Poor Plasma

The measurements were performed in a final volume of $75 \mu \mathrm{l}$ containing $50 \mu \mathrm{l}$ sample, $0.6 \mathrm{ng} / \mathrm{ml}$ recombinant tissue factor (2.5 $\mu \mathrm{l} 0.1 \times$ Innovin $^{\circledR}$, Dade Behring, Marburg, Germany), $2.7 \mu \mathrm{g} / \mathrm{ml}$ activated protein $\mathrm{C}\left(1 \mu 10.1 \times \mathrm{Xigris}^{\circledR}\right.$, Lilly \& Co., Giessen, Germany), $0.8 \mathrm{ng} / \mathrm{ml}$ phospholipids, isotonic saline, $\mathrm{CaCl}_{2}$, Tris buffer and fluorogenic substrate (Z-Gly-Gly-Arg-AMC from Bachem, Heidelberg, Germany) [17, 18]. Calibration was per- formed without recombinant tissue factor but with fondaparinux (Arixtra ${ }^{\circledR}$, Sanofi-Synthelabo, France) as a coagulation inhibitor and a dilution series of up to $20 \mathrm{n} M$ thrombin. The initial conversion rate of the calibration measurements is linearly correlated to the initial thrombin concentration.

Fluorescence intensity was detected using fluorimetric detection (Fluoroscan Ascent, Labsystem Helsinki, Finland) at wavelengths of $340 \mathrm{~nm}$ (excitation) and $440 \mathrm{~nm}$ (emission). The measurements lasted $240 \mathrm{~min}$ with a cycle time of $1 \mathrm{~min}$. All measurements were repeated three times.

\section{Mathematical Computation}

In plasma, $\alpha_{2}$-macroglobulin $\left(\alpha_{2} \mathrm{M}\right)$ builds a complex with free thrombin (IIa) that converts the fluorogenic substrate, but has no known clotting activity. Thus the influence of the complex $\alpha_{2} \mathrm{M} \cdot \mathrm{II}$ to the signal has to be subtracted by mathematical processing to obtain the thrombin curve. Assuming the formation of $\alpha_{2} \mathrm{M} \cdot$ IIa to be a pseudo 1st-order process [19] leads to:

$$
\frac{\partial}{\partial t}\left[\alpha_{2} M \cdot I I a\right]=k_{n} \cdot[I I a]
$$

With a 1st-order approximation of the conversion of the substrate with the same rate constant for IIa and $\alpha_{2} \mathrm{M} \cdot$ IIa [19] and a linear correlation between the concentration of the converted fluorogenic substrate and the obtained signal (which was given within the measurement range used), the signal $f$ is characterized by the differential time equation:

$$
\frac{\partial}{\partial t} f=k_{s} \cdot\left([F I I a]+k_{n} \int[F I I a] d t+A_{0}\right) \cdot\left(f_{\infty}-f\right)
$$

The maximum signal $f_{\bullet}$ (for complete conversion of the fluorogenic substrate), the rate constant $\mathrm{k}_{\mathrm{s}}$ for the conversion of the substrate by IIa or $\alpha_{2} \mathrm{M}$. IIa as well as the background activity $\mathrm{A}_{0}$ (mainly caused by APC) were determined by calibration. With the starting values $f_{0}=0,\left[\alpha_{2} \mathrm{M} \cdot \mathrm{IIa}\right]_{0}=0$ and $[\mathrm{IIa}]_{0}=0$ as well as the end condition $[\mathrm{IIa}]_{\mathrm{t}>\mathrm{te}}=0$, the rate constant $\mathrm{k}_{\mathrm{n}}$ may be obtained by a suitable nonlinear optimization method. We used a modified Marquardt-Levenberg algorithm.

In this article the average ETP values of the 8 references without any risk factors for thrombosis were set to $100 \%$. Thus ETP values of $<100 \%$ represent reduced thrombin generation and ETP values of $>100 \%$ represent increased thrombin generation compared to the references in our measurements.

Statistical analysis was performed by paired t test.

\section{Results}

\section{ETP in Samples of $F V_{\text {Leiden }}$ or $F V_{H R 2}$ Subjects}

In our measurements without addition of APC, the ETP values of samples with $\mathrm{FV}_{\mathrm{wt}}, \mathrm{FV}_{\mathrm{HR} 2}$ or $\mathrm{FV}_{\text {Leiden }}$ did not show any significant differences by detection. This is in accordance with results reported by other authors [11, 20]. In the presence of APC, a reduction in thrombin generation by an average of $46 \%$ was observed for reference plasma (wild-type for both FV mutations) compared with measurements without addition of APC. In our assay 


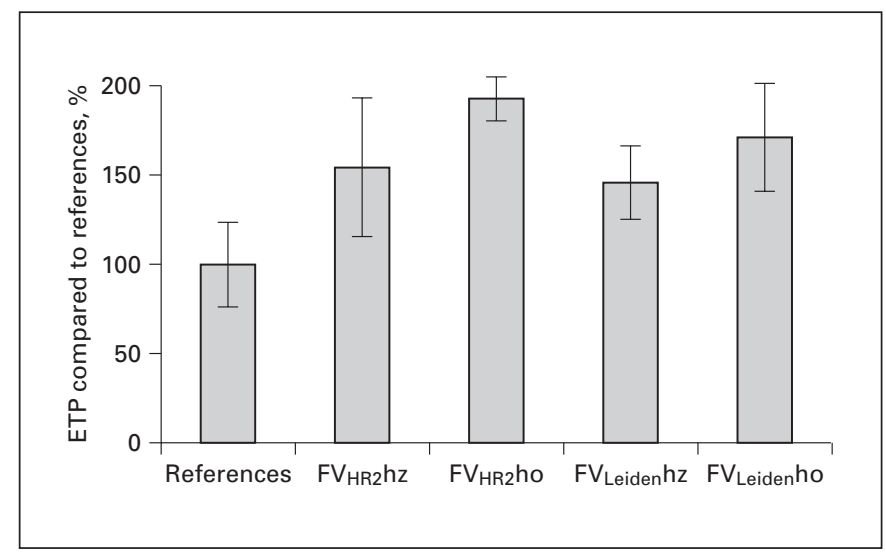

Fig. 1. Average ETP values in the presence of high APC concentrations for references (8 samples), heterozygous $\mathrm{FV}_{\mathrm{HR} 2}(\mathrm{n}=4)$, homozygous $\mathrm{FV}_{\mathrm{HR} 2}(\mathrm{n}=3)$, heterozygous $\mathrm{FV}_{\text {Leiden }}(\mathrm{n}=4)$ and homozygous $\mathrm{FV}_{\text {Leiden }}(\mathrm{n}=3)$ individuals.

with APC, obvious differences appear $(\mathrm{p}<0.05)$ between reference samples and samples from subjects with $\mathrm{FV}_{\text {Leiden }}$ or $\mathrm{FV}_{\mathrm{HR} 2}$ mutations (fig. 1).

In samples with the $\mathrm{FV}_{\text {Leiden }}$ and $\mathrm{FV}_{\mathrm{HR} 2}$ mutations, thrombin generation is less reduced for both homozygous and heterozygous entities by addition of APC compared to the references. This means that in the presence of APC, $\mathrm{FV}_{\text {Leiden }}$ as well as $\mathrm{FV}_{\mathrm{HR} 2}$ lead to increased ETP values compared to the references.

These data indicate a dysfunction in the regulation of the coagulation system which results from the presence of $\mathrm{FV}_{\text {Leiden }}$ or $\mathrm{FV}_{\mathrm{HR} 2}$. The diminished regulation causes a higher thrombin generation compared to the references without these mutations.

No influence of a history of thrombosis on ETP was observed.

In the patients homozygous for $\mathrm{FV}_{\mathrm{HR} 2}$ the thrombin generation in the corresponding plasma samples was below the detection limit during oral anticoagulation (phenprocumon). Four weeks after termination of medication, the ETP values remained below the reference value. On repeat testing 4 and 6 weeks after oral anticoagulation had been stopped, ETP markedly increased above the reference value (fig. 2).

The difference between the ETP values 4 and 6 weeks after treatment had been stopped indicates the sensitivity of this method to low concentrations of vitamin $\mathrm{K}$ antagonists.

Influence of $\mathrm{FV}_{\mathrm{HR} 2}$ on $\mathrm{ETP}$

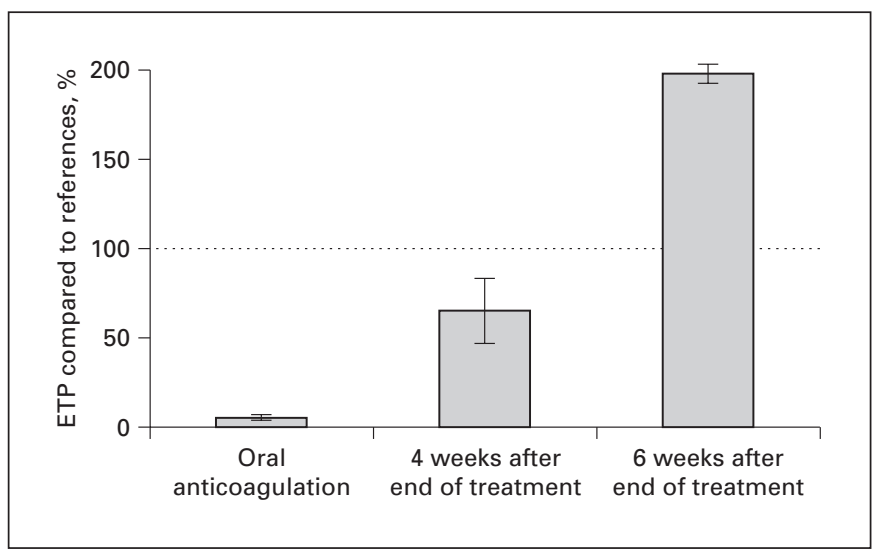

Fig. 2. Effect of oral anticoagulation on ETP in the presence of APC in patients homozygous for $\mathrm{FV}_{\mathrm{HR} 2}$. Average ETP values of samples from 2 patients collected during and after oral anticoagulation (phenprocumon) compared to the average reference values obtained from 8 persons with FV wild-type for both FV mutations (fig. 1).

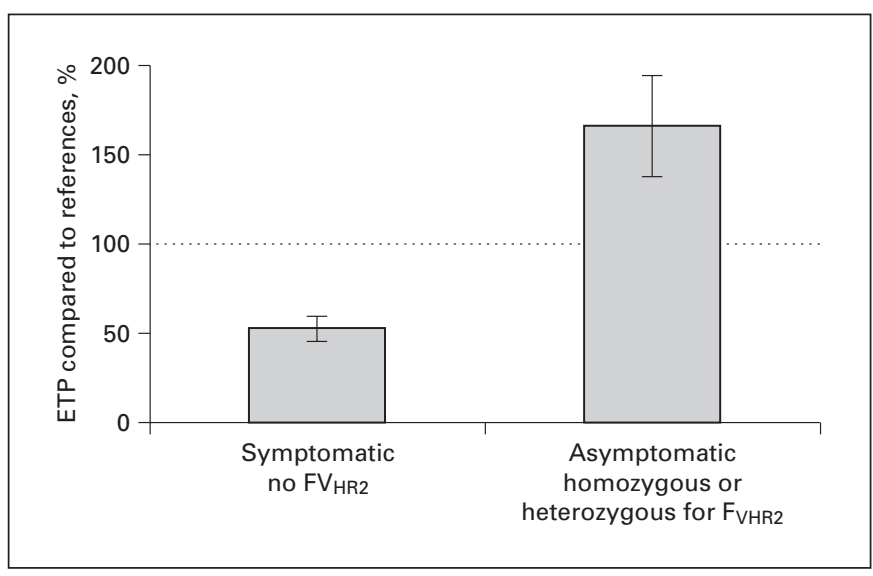

Fig. 3. Average ETP values of samples from patients homozygous for FVII $_{\mathrm{A} 294 \mathrm{~V}}$ with bleeding symptoms (2 samples) and without bleeding symptoms ( 2 samples) compared to the average reference values obtained from 8 persons with $\mathrm{FV}$ wild-type for both $\mathrm{FV} \mathrm{mu-}$ tations (fig. 1).

\section{ETP in FVII-Deficient Patients Homozygous for Mutation $\mathrm{FVII}_{A 294 \mathrm{~V}}$}

For the samples of patients homozygous for the mutation $\mathrm{FVII}_{\mathrm{A} 294 \mathrm{~V}}$ the ETP measurements in the presence of APC resulted in heterogeneous data despite the same FVII genotype. However, a very good correlation was observed between ETP on the one hand and the presence of $\mathrm{FV}_{\mathrm{HR} 2}$ and bleeding symptoms on the other (fig. 3). ETP 
in patients with bleeding symptoms (epistaxis, gum bleeding, menorrhagia or hemarthrosis) was markedly below the reference values. None of these patients carried $\mathrm{FV}_{\mathrm{HR}}$ or $\mathrm{FV}_{\text {Leiden. }}$. The ETP values of the asymptomatic cases were increased compared to the reference values. These asymptomatic persons were heterozygous or homozygous for $\mathrm{FV}_{\mathrm{HR} 2}$ and did not carry $\mathrm{FV}_{\text {Leiden }}$.

\section{Discussion}

\section{$F V_{H R 2}$ Increases ETP with APC-Like F $V_{\text {Leiden }}$}

The endogenous thrombin potential is a sensitive indicator of hyper- and hypocoagulability [21, 22]. APC resistance as demonstrated by ETP is associated with an increased risk for venous thromboembolism [23]. An association between the APC resistance of $\mathrm{FV}_{\text {Leiden }}$ and an increased risk of venous thrombosis has already been published by other authors [1-3].

The present study shows an increased thrombin generation in the presence of APC both for $\mathrm{FV}_{\text {Leiden }}$ and for $\mathrm{FV}_{\mathrm{HR} 2}$ compared to the references. The ETP values are correlated to the presence of $\mathrm{FV}_{\mathrm{HR} 2}$ and likewise to the presence of $\mathrm{FV}_{\text {Leiden. }}$ Our measurements show an increased ETP in 3 subjects homozygous for $\mathrm{FV}_{\mathrm{HR} 2}$ and for the first time in 4 heterozygous individuals. This increase is comparable to that in subjects with $\mathrm{FV}_{\text {Leiden }}(\mathrm{p}>0.3)$.

Recently a similar result was reported by Castoldi et al. [11] for a single individual homozygous for $\mathrm{FV}_{\mathrm{HR} 2}$.

These high ETP values are caused by an APC resistance, which is an indication for an increased risk of venous thrombosis [23]. Thus, our results provide evidence for the role of $\mathrm{FV}_{\mathrm{HR} 2}$ as a risk factor for venous thrombosis in homozygous patients through an increased thrombin generation. The increased ETP values in the presence of APC also suggest an increased risk of thrombosis for heterozygous $\mathrm{FV}_{\mathrm{HR} 2}$. However, this is not conclusive due to the wide data range. Thus, further investigation with a large number of subjects is necessary to confirm this statement.

\section{Clinical Manifestation in Rare Bleeding Disorders and Thrombin Generation}

Several cases of patients with severe deficiency of factors VIII (hemophilia A) [24] or factor IX (hemophilia B) [25] have been reported which show only mild bleeding symptoms because of the simultaneous occurrence of $\mathrm{FV}_{\text {Leiden }}$. The mild clinical phenotype can be explained by an increased thrombin generation as a consequence of the APC resistance of $\mathrm{FV}_{\text {Leiden }}$ [26]. A moderating effect of $\mathrm{FV}_{\text {Leiden }}$ on bleeding symptoms has also been described recently in patients homozygous for the mutation $\mathrm{FVII}_{9726}+5 \mathrm{G}>\mathrm{A}\left(\mathrm{FVII}_{\text {Lazio }}\right)$ with 1 patient carrying heterozygous $\mathrm{FV}_{\text {Leiden }}[20]$. However other groups have not confirmed this moderating effect of $\mathrm{FV}_{\text {Leiden }}$ in severe hemophilia A patients [27, 28]. Thus, mild clinical expression of severe hemophilia cannot be exclusively attributed to the coexistent presence of $\mathrm{FV}_{\text {Leiden }}$ [29].

In this study we have shown that the presence of $\mathrm{FV}_{\text {Leiden }}$ and of the $\mathrm{FV}_{\mathrm{HR} 2}$ alleles (heterozygous or homozygous) is correlated with an increase of the thrombin generation in the corresponding plasma samples. Our measurements show that homozygous $\mathrm{FV}_{\mathrm{HR} 2}$ is correlated with an increased thrombin generation comparable to FVLeiden. On this basis the effect of $\mathrm{FV}_{\mathrm{HR} 2}$ on thrombin generation was studied in homozygous FVII-deficient patients (caused by the same mutations) of variable severity.

In the Greifswald FVII Deficiency Study we described a great variability in the clinical manifestation of inherited FVII deficiency [15]. The most frequent $F 7$ gene lesion among FVII-deficient patients in Germany is the missense mutation A294V [16].

Among 4 homozygous patients with the identical mutation A294V, 2 had bleeding symptoms and 2 never had spontaneous bleeding symptoms related to the FVII:C deficiency. ETP measurements in the plasma samples of these patients carrying the homozygous mutation FVII $_{\mathrm{A} 294 \mathrm{~V}}$ showed the reported correlation of severity and thrombin generation. The asymptomatic homozygous A294V patients have a significantly higher thrombin generation than symptomatic homozygous patients for the same mutation.

On the other hand, the symptomatic FVII-deficient homozygous patients are characterized by the FV wildtype and the asymptomatic patients by the $\mathrm{FV}_{\mathrm{HR} 2}$ genotype (homozygous or heterozygous). An association is shown between severity and ETP (measured with addition of APC) as well as the presence of $\mathrm{FV}_{\mathrm{HR} 2}$.

In analogy to $\mathrm{FV}_{\text {Leiden }}$ our findings may allow the conclusion that the APC resistance of $\mathrm{FV}_{\mathrm{HR} 2}$ may moderate the severity of bleeding symptoms in patients with inherited bleeding disorders by an increased thrombin generation.

These studies indicate that the presence of the thrombotic risk factors, $\mathrm{FV}_{\text {Leiden }}$ or $\mathrm{FV}_{\mathrm{HR} 2}$, may modulate the degree of bleeding symptoms in patients with FVII deficiency, similar to that observed in patients with hemophilia A [24]. Further investigation on homozygous patients with identical mutations is necessary to verify these findings. 


\section{Acknowledgements}

The authors thank Angelika Batorova (National Haemophilia Centre, Institute of Haematology and Blood Transfusion, University Hospital, Bratislava, Slovakia), Volker Aumann (Universitäts-
Kinderklinik, Kiel, Germany), Harald Lenk (Universitäts-Kinderklinik, Leipzig, Germany) and Sirak Petros (Clinical Haemostaseology, Medical Clinic I, University of Leipzig, Leipzig, Germany) for providing the plasma samples of $\mathrm{FVII}_{\mathrm{A} 294 \mathrm{~V}}$ patients.

\section{References}

1 Dahlbäck B, Carlsson M, Svensson P: Familial thrombophilia due to a previously unrecognized mechanism characterized by poor anticoagulant response to activated protein $\mathrm{C}$ : prediction of a cofactor to activated protein $\mathrm{C}$. Proc Natl Acad Sci USA 1993;90:1004-1008.

$\checkmark 2$ Rosendaal FR, Koster JP, Vandenbroucke JP, Reitsma PH: High risk of thrombosis in patients homozygous for factor V Leiden (activated protein C resistance). Blood 1995;85: 1504-1508.

>3 Ridker PM, Hennekens CH, Lindpaintner K, Stampfer MJ, Eisenberg PR, Miletich JP: Mutation in the gene coding for coagulation factor $\mathrm{V}$ and the risk of myocardial infarction, stroke, and venous thrombosis in apparently healthy men. N Engl J Med 1995;332:912-917.

$\checkmark 4$ Koster T, Rosendaal FR, de Ronde H, Briët E, Vandenbroucke JP, Bertina RM: Venous thrombosis due to poor anticoagulant response to activated protein C: Leiden Thrombophilia Study. Lancet 1993;342:1503-1506.

$\checkmark 5$ Bertina RM, Koeleman BPC, Koster T, Rosendaal FR, Dirven RJ, de Ronde H, van der Velden PA, Reitsma PJ: Mutation in blood coagulation factor $\mathrm{V}$ associated with resistance to activated protein C. Nature 1994;369:6467.

6 Greengard JS, Sun X, Xu X, Fernandez JA, Griffin JH, Evatt B : Activated protein C resistance caused by $\operatorname{Arg} 506 \rightarrow$ Gln mutation in factor Va. Lancet 1994;343:1361-1362.

7 Voorberg J, Roelse J, Koopman R, Büller H, Berends F, ten Cate JW, Mertens K, van Mourik JA: Association of idiopathic venous thromboembolism with single point mutation at Arg506 of factor V. Lancet 1994;343:15351536.

$>8$ Zöller B, Dahlbäck B: Linkage between inherited resistance to activated protein $\mathrm{C}$ and factor $\mathrm{V}$ gene mutation in venous thrombosis. Lancet 1994;343:1536-1538.

$>9$ Castaman G, Faioni EM, Tosetto A, Bernardi F: The factor V HR2 haplotype and the risk of venous thrombosis: a meta-analysis. Haematologica 2003;88:1182-189.

10 Dargaud Y, Meunier S, Negrier C: Haemophilia and thrombophilia: an unexpected association! Haemophilia 2004;10:319-326.

-11 Castoldi E, Brugge JM, Nicolaes DAF, Girelli D, Tans G, Rosing J: Impaired APC cofactor activity of factor $\mathrm{V}$ plays a major role in the APC resistance associated with the factor V Leiden (R506Q) and R2 (H1299R) mutations. Blood 2004; 103:4173-4179.
12 Castoldi E, Rosing J, Girelli D, Hoekema L, Lunghi B, Migozzi F, Ferraresi P, Friso S, Corrocher R, Tans G, Bernardi F: Mutations in the R2 FV gene affect the ratio between the two FV isoforms in plasma. Thromb Haemost 2000;83:362-365.

13 Bernardi F, Faioni EM, Castoldi E, Lunghi B, Castaman G, Sacchi E, Mannucci PM: A factor $\mathrm{V}$ genetic component differing from factor $\mathrm{V}$ $\mathrm{R} 506 \mathrm{Q}$ contributes to the activated protein $\mathrm{C}$ resistance phenotype. Blood 1997;90:15521557.

14 Herrmann FH, Salazar-Sanchez L, JimenezArce G, Grimm R, Schroder W: High prevalence of FVHR2 polymorphism in Costa Rican Indians who have no FVL. Thromb Haemost 2001;85:1020-1021.

15 Herrmann FH, Wulff K, Auberger K, Aumann V, Bergmann F, Bratanoff E, Franke D, Grundeis M, Kreuz W, Lenk H, Losonszy H, Maak B, Marx G, Mauz-Körholz C, Pollmann H, Serban M, Sutor A, Syrbe G, Vogel G, Weinstock N, Wenzel E, Wulff K: Molecular biology and clinical manifestation of hereditary factor VII deficiency. Semin Thromb Hemost 2000;26:393-400.

16 Wulff K, Herrmann FH. Twenty-two novel mutations of the factor VII gene in factor VII deficiency. Hum Mutat 2000;15:489-496.

17 Siegemund A, Petros S, Siegemund T, Scholz U, Seyfarth H-J, Engelmann L: The endogenous thrombin potential and high levels of coagulation factor VIII, factor IX and factor XI. Blood Coagul Fibrinolysis 2004; 15:241-244.

18 Siegemund T, Petros S, Siegemund A, Scholz U, Engelmann L: Thrombin generation in severe haemophilia $\mathrm{A}$ and $\mathrm{B}$ : the endogenous thrombin potential in platelet-rich plasma. Thromb Haemost 2003;90:781-786.

19 Hemker HC, Béguin S: Thrombin generation in plasma: its assessment via the endogenous thrombin potential. Thromb Haemost 1995; 74:134-138.

20 Castoldi E, Govers-Riemslag JWP, Pinotti M, Biondini D, Tans G, Berrettini M, Mazzucconi MG, Bernardi F, Rosing J: Coinheritance of factor $\mathrm{V}(\mathrm{FV})$ Leiden enhances thrombin formation and is associated with a mild bleeding phenotype in patients homozygous for the FVII 9726 + 5G>A (FVII Lazio) mutation. Blood 2003; 102:4014-4020.
1 Zotz RB, Gerhardt A, Kluft C, Scharf RE: Venous thromboembolism during pregnancy is not associated with persistent elevated activated protein $\mathrm{C}$ (APC) sensitivity ratio based on the endogenous thrombin potential. Thromb Haemost 2005;93:306-310.

22 Wielders S, Mukherjee M, Michiels J, Rijkers DTS, Cambus JP, Knebel RWC, Kakkar V, Hemker HC: The routine determination of the endogenous thrombin potential, first results in different forms of hyper- and hypocoagulability. Thromb Haemost 1997;77:629636

23 Tans G, Rosendaal FR, Curvers J, Thomassen MCL, Bertina RM, Rosing J: APC resistance determined with the endogenous thrombin generation potential is associated with venous thrombosis: a blinded clinical evaluation (abstract 640). 17th Congr Int Soc Thromb Haemost, Washington, 1999. Thromb Haemost 1999;82(suppl):202.

24 Nichols WC, Amano K, Cacheris PM, Figueiredo MS, Michaelides K, Schwaab R, Hoyer L, Kaufman RJ, Ginsburg D: Moderation of hemophilia A phenotype by the factor V R506Q mutation. Blood 1996;88:1183-1187.

-25 Vianello F, Belvini D, Dal Bello F, Tagariello G, Zanon E, Lombardi A-M, Zerbinati P, Girolami A: Mild bleeding diathesis in a boy with combined severe haemophilia B $(\mathrm{C} 10400 \rightarrow \mathrm{T})$ and heterozygous factor V Leiden. Haemophilia $2001 ; 7: 511-514$

26 van't Veer C, Golden NJ, Kalafatis M, Simioni P, Bertina RM, Mann KG: An in vitro analysis of the combination of hemophilia A and factor V(LEIDEN). Blood 1997;90:30673072.

27 Arbini AA, Mannucci PM, Bauer KA: Low prevalence of the factor $\mathrm{V}$ Leiden Mutation among 'severe' haemophiliacs with a 'milder' bleeding diathesis. Thromb Haemost 1995; 74 $1255-1258$

-28 Arruda VR, Annichio-Bizzachi JM, Antunes SV, Costa FF: Association of severe haemophilia A and factor V Leiden: report of three cases. Haemophilia 1996;2:51-53.

29 Chan J, Weinmann AF, Thompson AR: Factor V Arg/Gln 506 has no dominant influence on the severity of haemophilia when inherited concurrently. Thromb Haemost 1995;73: 1368 . 